\title{
Large measles outbreak in Geneva, Switzerland, January to August 2011: descriptive epidemiology and demonstration of quarantine effectiveness
}

E Delaporte ${ }^{1}$, C A Wyler Lazarevic ${ }^{2}$, A Iten ${ }^{3}$, P Sudre (philippe.sudre@etat.ge.ch) ${ }^{1}$

1. Epidemiology and infectious diseases section, Cantonal Health Service, General Directorate for Health, Geneva, Switzerland

2. Youth Health Service, Department of Education, Geneva, Switzerland

3. Hospital Infection control Service, Cantonal University Hospital of Geneva, Geneva, Switzerland

Citation style for this article:

Delaporte E, Wyler Lazarevic CA, Iten A, Sudre P. Large measles outbreak in Geneva, Switzerland, January to August 2011: descriptive epidemiology and demonstration of quarantine effectiveness . Euro Surveill. 2013;18(6):pii=20395. Available online: http://www.eurosurveillance.org/ViewArticle. aspx?Articleld $=20395$

Between January and August 2011, the canton of Geneva, Switzerland, experienced a large measles outbreak with 219 cases (47 cases per 100,000 inhabitants) in the context of an extensive epidemic in a neighbouring region of France. Most cases were young adults (median age: 18 years), often unaware of their vaccination status. The vast majority of cases were either not $(81 \%)$ or incompletely vaccinated $(8 \%)$. Thirty clusters with a total of 119 cases and a median cluster size of three (range: 2-15 cases) were identified. Overall, 44 cases were imported or linked to imported cases. Of 73 contacts of cases who were quarantined, 50 developed measles and caused six secondary cases. This compares to 81 secondary cases among 173 non-quarantined cases (relative risk: 0.26 ; 95\% confidence interval: 0.06-0.65), demonstrating the effectiveness of well targeted quarantine measures in reducing transmission.

\section{Introduction}

At the end of 2010, the objective of the World Health Organization (WHO) to interrupt the endemic transmission of measles appeared to be within reach in the canton of Geneva, Switzerland. Although several outbreaks had occurred between 2003 and 2008, the number of cases decreased from the summer 2008 until 2010. Fifty measles cases had been notified in 2003 (12 cases per 100,000 inhabitants), mostly isolated or in small clusters related to imported cases, and in 2010, only nine cases were notified (two cases per 100,000 inhabitants) [1-3]. During the same period, measles immunisation coverage with two doses of measles-mumps-rubella vaccine (MMR) was close to the $95 \%$ elimination threshold, with $91.7 \%$ for children aged 28 months and $92.3 \%$ for children aged between five and six years $[1,4-7]$.

Against this context, however, a large outbreak started in January 2011 [8]. It lasted seven months, and finally 219 cases were notified to local health authorities (47 cases per 100,000 inhabitants). In the same period, a large outbreak was occurring in the neighbouring region of Rhône-Alpes, France, where 6,037 cases were reported from October 2010 to September 2011 [9]. Geneva canton (population 467,000) shares $96 \%$ (103 of $107.5 \mathrm{~km}$ ) of its border with France, and approximately 80,000 persons cross the border every day.

The aim of this report is to describe the measles outbreak that occurred in Geneva between January and August 2011, measures taken to reduce its extension and the impact of quarantine on disease transmissions.

\section{Methods}

\section{Measles case notification}

In Switzerland, measles notification has been mandatory since 1999. Physicians report to local health authorities within 24 hours any patient presenting with maculopapular rash associated with fever and any of the following symptoms: cough, coryza or conjunctivitis. Initial notification is followed by a more detailed description of the case including self-reported vaccination status. Notification of confirmed cases by laboratories is also mandatory within 24 hours. In general, there are therefore two nominative notifications per case. Patients who do not seek medical attention are not officially reported, but during an outbreak, they are identified through contact investigation by the cantonal health authority and counted as cases if they fit the case definition (active case finding).

\section{Case definition and classification}

The following case definitions, slightly more sensitive than those recommended by the European Centre for Disease Prevention and Control (ECDC), were used in this investigation [10]. A confirmed case was a person i) with a positive laboratory test and at least one of the clinical criteria of measles listed above (laboratory-confirmed case) or ii) who met the clinical case definition and was epidemiologically linked to a laboratory-confirmed case (epidemiologically linked case). A probable 
case was a person who met the clinical case definition with no epidemiological link to a laboratory-confirmed case. A possible case was a person without a positive laboratory result who did not meet all clinical case definition criteria.

\section{Laboratory tests}

Laboratory confirmation tests included serum IgM and IgG measurements in combination to distinguish between acute infection and immunity, or PCR for measles virus RNA in throat swab or oral fluid. Genetic characterisation was carried out either at the Central Virology Laboratory of Geneva University Hospital or at the Robert-Koch Institute in Berlin, Germany, to determine genotype by sequence analysis of the variable part of the neuraminidase $(\mathrm{N})$ gene and the haemagglutinin $(\mathrm{H})$ gene.

Suspected cases with two negative IgM tests or one negative IgM test and with a negative PCR result, and those with a single positive IgM test without any clinical symptoms of measles, were excluded. Cases included in this report were residents of the canton Geneva presenting with clinical symptoms of measles between 1 January and 31 August 2011.

\section{Outbreak control evaluation}

An evaluation of the ways this outbreak was managed was performed in September and October of 2011 using a standard questionnaire. Its aim was to assess how partner institutions perceived the various aspects of outbreak response including communication, surveillance, control and contact tracing activities. All 38 institutions involved in controlling the outbreak or their representatives received this questionnaire. All questionnaire items were rated on a scale of 1 (not satisfactory) to 5 (very satisfactory).

The statistical comparison of incidence following exposure to quarantined and non-quarantined cases was conducted using StatXact version 4.0.1 software [11].

\section{Outbreak description}

From 1 January until 31 August 2011, 219 cases were reported, 182 (83\%) through the notification system and $37(17 \%)$ by active case finding. There were 195 (89\%) confirmed, 16 (7\%) probable and eight (4\%) possible cases. Among the confirmed cases, 138 were laboratory-confirmed and 57 were epidemiologically linked cases.

An additional 62 cases diagnosed in Geneva and reported to the health authorities are not included in this report because they were either French residents $(n=44)$, lived in the canton of Vaud $(n=14)$ or in another canton or country $(n=4)$. These patients, however, all worked, attended school or consulted a physician in Geneva. Another 37 reported cases were ruled out as non-measles cases.
Sequencing of 31 measles viruses isolated during the outbreak was performed. Genotype D4 was isolated in all 23 samples obtained from residents of the canton Geneva as well as in seven samples from French residents. One D9 serotype was identified in a tourist from the Philippines visiting Geneva.

The epidemic curve is presented in Figure 1. Of the 219 cases, 44 (20\%) could be documented as imported cases $(n=21)$ or epidemiologically linked, directly or indirectly, to an imported case $(n=23)$. These cases came from or were epidemiologically linked to cases from the French département of Haute-Savoie $(n=25)$, the French département of Ain $(n=4)$, other départements of France $(n=7)$, the canton of Vaud $(n=6)$, Argentina $(n=1)$ and Poland $(n=1)$. During the first eight weeks of the epidemic, a substantial proportion of the cases (19 of 49 ) were imported or linked to imported cases.

Among the 211 confirmed and probable cases, 98 (46\%) were male. The median age was 18 years (range: 11 months-59 years). For 189 (90\%) of those self-reported information on immunisation status was available. Some $154(81 \%)$ had not been vaccinated with MMR vaccine, $16(8 \%)$ had received one dose, $12(6 \%)$ at least two doses and seven were vaccinated with an unknown number of doses. Among the 154 unvaccinated cases all but five who were older than 47 years, (i.e. born in or before 1963 , the age at which measles vaccination is no longer recommended in Switzerland) were eligible for vaccination (97\%). Cases are presented by age group and vaccination status in Figure 2. No catch-up campaigns were done during this epidemic. However, catch-up is recommended in the Swiss vaccination plan for all persons born after 1963 .

\section{FIGURE 2}

Confirmed and probable measles cases by age and self-reported vaccination status, Geneva, Switzerland, 1 January-31 August $2011(\mathrm{n}=211)$

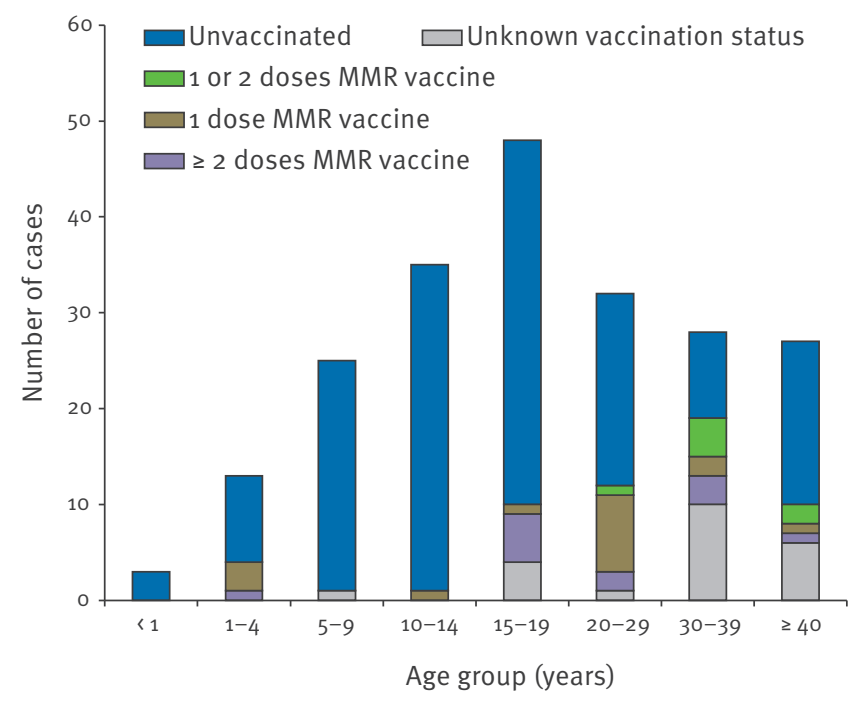

MMR: measles-mumps-rubella. 


\section{FIGURE 1}

Measles cases by month of rash onset, Geneva, Switzerland, 2003-11 ( $\mathrm{n}=219)$
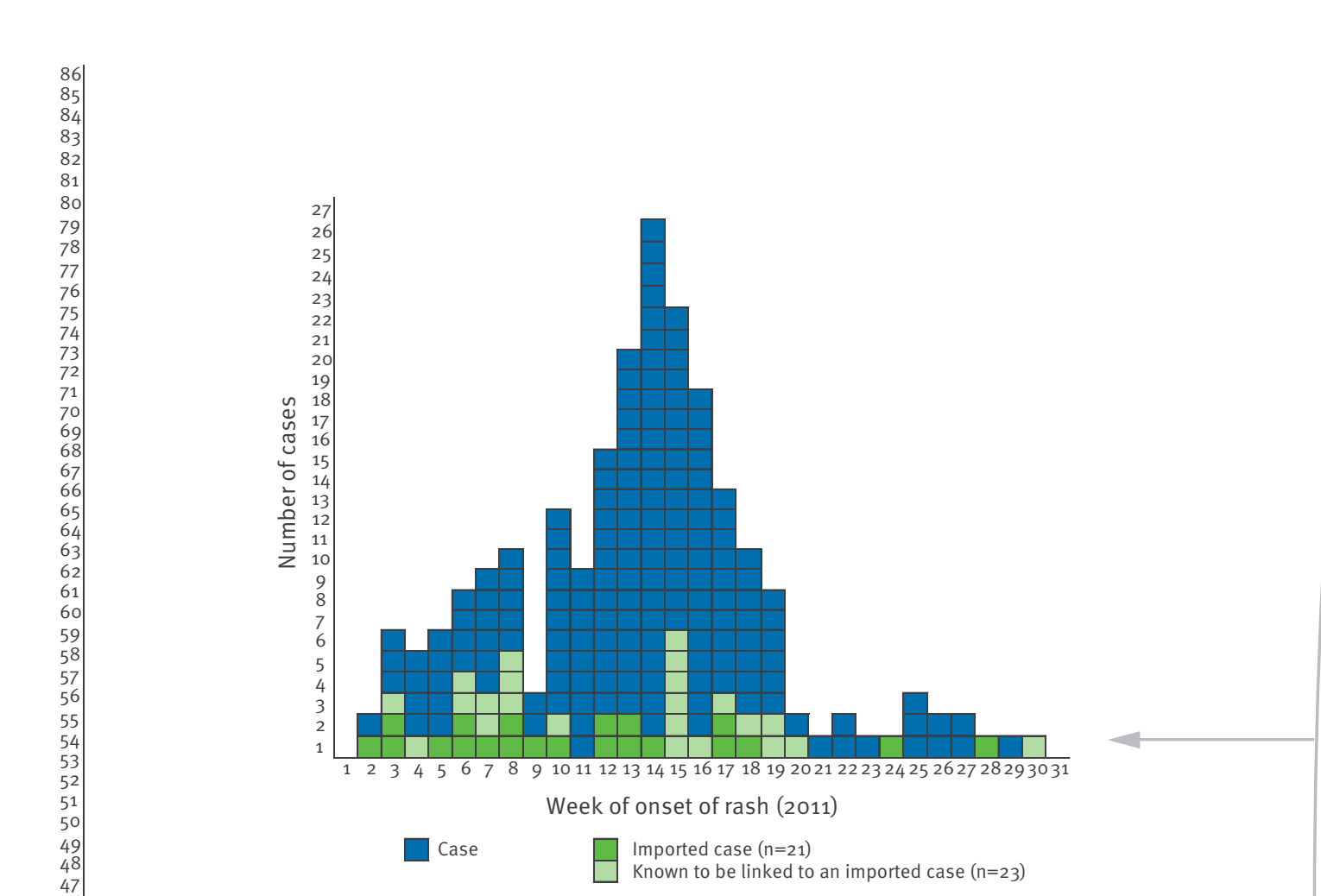

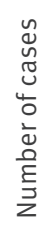

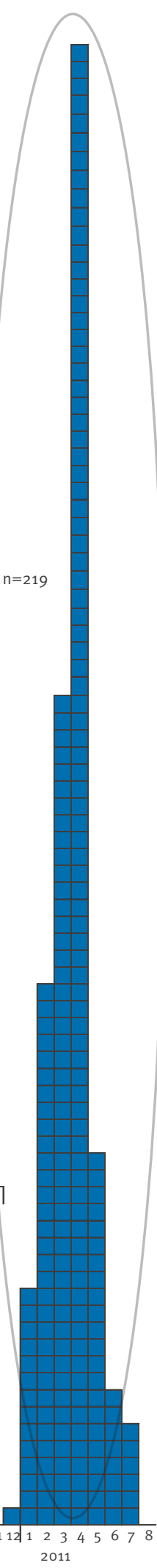

Month of onset of rash (2011) 
Mode of acquisition of measles, Geneva, Switzerland, 1 January-31 August 2011 (n=123)

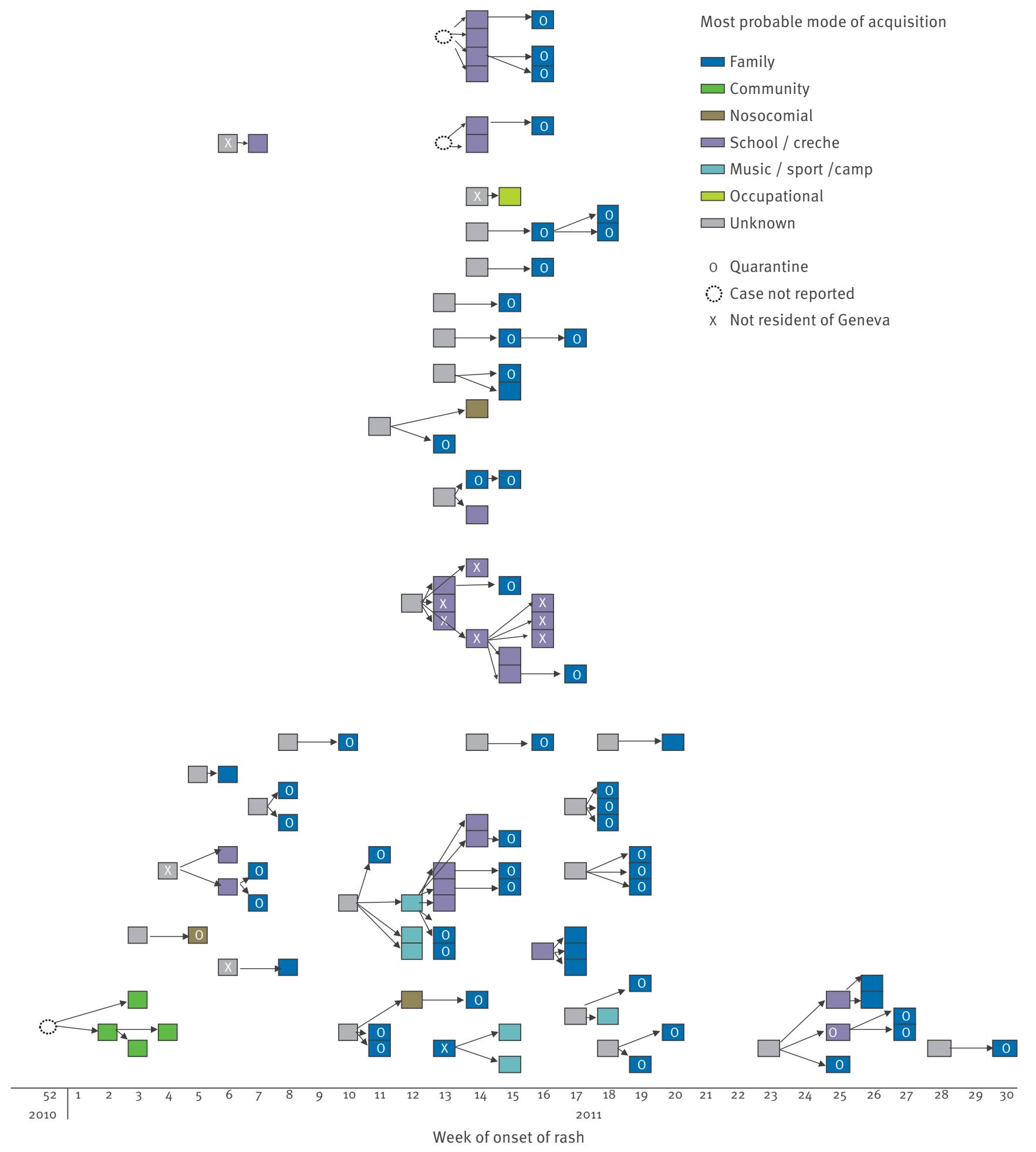

Cases not resident in Geneva are included for completeness of cluster description. 
Of 211 cases, 18 (9\%) presented with at least one complication such as pneumonia $(n=11)$, encephalitis $(n=1)$, bronchitis $(n=1)$, other lower respiratory disease $(n=2)$, otitis $(n=2)$, keratitis $(n=1)$ and exacerbation of cystic fibrosis $(n=1)$. Seventeen ( $8 \%)$ patients were hospitalised, one of them for 10 days in intensive care with respiratory failure. The other causes of hospitalisations were encephalitis $(n=1)$, pneumonia $(n=4)$, hypoxaemia $(n=4)$, general alteration of heath status $(n=4)$, and two cases stayed overnight for clinical observation. The precise cause of hospitalisation remains unknown for two patients. There were no deaths and all patients recovered. The median duration of hospitalisation was four days (range: 1-14 days). The median age of hospitalised patients was 33 years (range: 7-52 years). Among the 14 (82\%) hospitalised patients for whom the vaccination status was known, 11 had not been vaccinated and one had been completely vaccinated (two doses).

We identified 31 transmission clusters (Figure 3) with 123 cases including 12 who were not residents of Geneva. There were two clusters of three generations of cases including 13 and 15 cases. The other clusters included two to eight cases in one or two generations (median cluster size: 3). Transmission among residents of Geneva occurred within families ( $n=54$ cases), in schools $(n=20)$ and daycare $(n=1)$, among friends $(n=4)$, in health service $(n=3)$, during sporting or musical events $(n=5)$, in the workplace $(n=1)$ and during a one-week camp $(n=1)$. There were an additional 22 single cases (index case of each cluster) with unknown mode of acquisition.

\section{Control measures}

Control measures in the Geneva canton have been previously described $[8,12]$. They were implemented as early as possible by local health authorities and school health services without waiting for laboratory confirmation (Figure 4). Extensive and rapid contact tracing was conducted as an emergency measure so that contacts and relatives of cases could be informed and their vaccination or immunisation status assessed. When a case had unvaccinated or non-immune close contacts, either siblings or classmates, these were quarantined at home for 18 days after last contact or after onset of the case's rash. Although immediate postexposure vaccination may prevent measles, it does not later during quarantine. In addition, because vaccinerelated symptoms may mimic measles, it may discredit vaccination itself in this often reluctant population. For these reasons, unless immediate post exposure ( $172 \mathrm{~h}$ ) vaccination was done, vaccination was recommended at the end of the quarantine period if measles had not occurred. Early in the course of the epidemic, all parents of children attending school or nursery were sent a letter informing them about the outbreak and the importance of vaccinating their children. They were also informed about quarantine of unvaccinated contacts.

Of 73 exposed unvaccinated or non-immune persons who were quarantined, 50 developed measles. Only six instances of subsequent transmission occurred, all among household members and none in the community. The 173 cases which occurred among non-quarantined cases were associated with 81 secondary cases, of which 48 occurred among household members and 33 in the community. As indicated in the Table, quarantine reduced the overall risk of transmission by $74 \%$ ( $12 \%$ versus $47 \%$; relative risk (RR): $0.26 ; 95 \%$ confidence interval $(\mathrm{Cl}): 0.06-0.56)$. The reduction of the risk of transmission was obviously lower among household members ( $12 \%$ versus $28 \%$; RR: $0.43 ; 95 \%$ $\mathrm{Cl}: 0.09-1.00)$ and was major, $95 \%$, in the community (o\% versus 19\%; RR: 0.05; 95\% Cl: 0.00-0.69). Case finding and contact tracing was identical regardless of quarantine status.

Health authorities regularly informed emergency medical services, the media and the public. In addition, local physicians were sent by email epidemiological updates and practical information in connection with their role in outbreak control. Early in the epidemic, they were advised to reduce the age of first measles vaccination from 12 to nine months. Press releases, individual emails to all students at Geneva University, information letters to highschool students, directors of schools and daycare centres were also sent out. Young adults were the main target of mass communication and they were advised to verify their immunisation status and be vaccinated if necessary.

Of the 38 partner institutions involved in outbreak control who received the evaluation questionnaire, 19 responded. Their overall level of satisfaction was fairly

TABLE

Rate of transmission of measles by measures of quarantine, risk ratios and p value, Geneva, Switzerland, 1 January-31 August 2011

\begin{tabular}{|c|c|c|c|c|c|c|}
\hline \multirow{2}{*}{ Type of transmission } & \multicolumn{2}{|c|}{ Quarantine $(n=50)$} & \multicolumn{2}{|c|}{ No quarantine $(n=173)$} & \multirow{2}{*}{$\begin{array}{c}\text { Risk ratio } \\
\text { (95\% confidence } \\
\text { interval) }\end{array}$} & \multirow{2}{*}{$p$ value } \\
\hline & Transmission & Rate & Transmission & Rate & & \\
\hline Total & 6 & $12 \%$ & 81 & $47 \%$ & $0.26[0.06-0.56]$ & 0.002 \\
\hline Within household & 6 & $12 \%$ & 48 & $28 \%$ & $0.43[0.09-1.00]$ & 0.051 \\
\hline Outside household & 0 & $0 \%$ & 33 & $19 \%$ & $0.05[0.00-0.69]$ & 0.01 \\
\hline
\end{tabular}




\section{FIGURE 4}

Control measures during the measles outbreak, Geneva, Switzerland, 1 January-31 August 2011

\section{Suspected case of measles}

\section{Notification by physicians to SMC within $24 \mathrm{~h}$}

Laboratory test for primarya cases and cases isolated at home for four days after rash onset

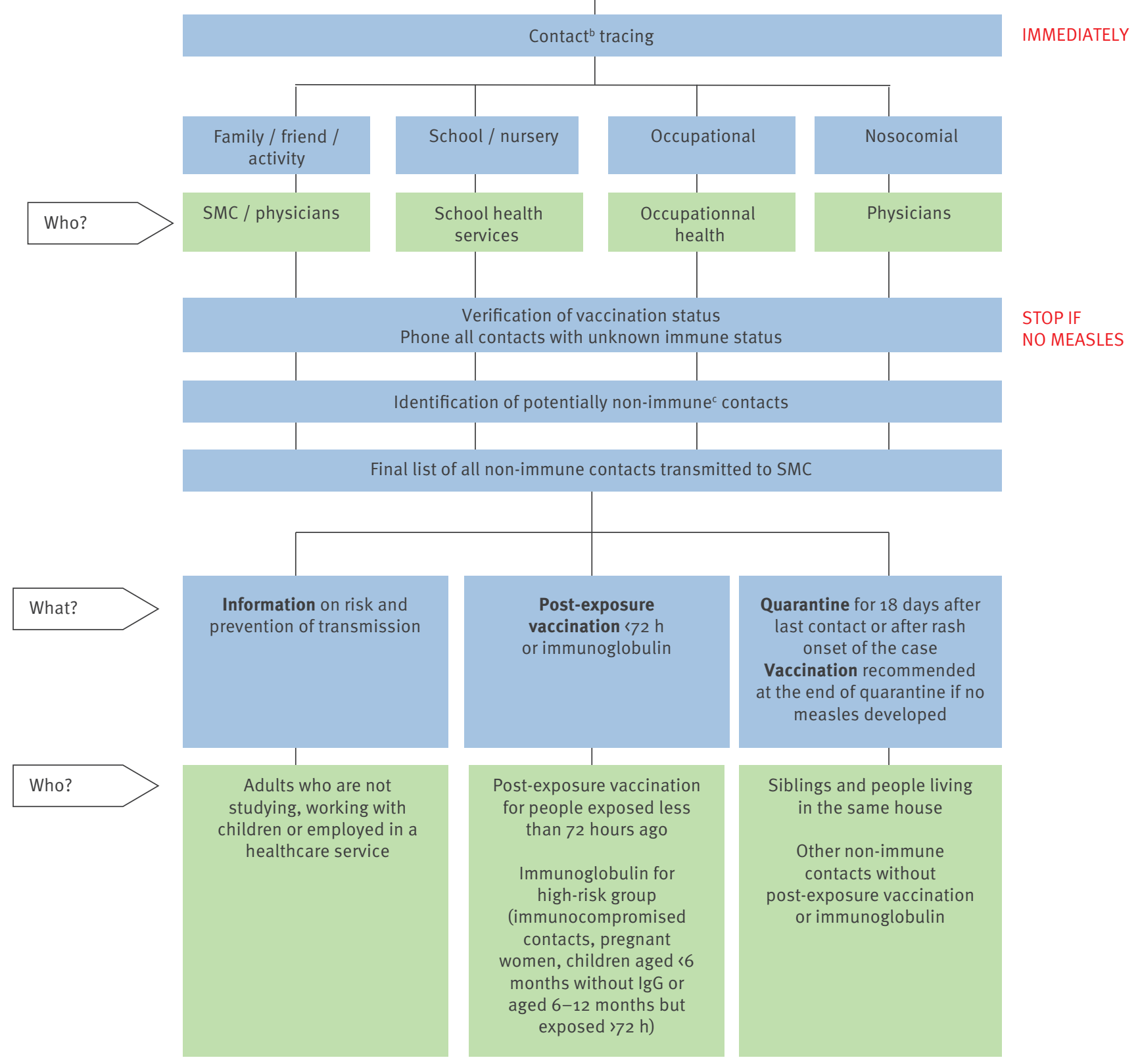

SMC: Cantonal Health Service.

a A primary case was defined as a measles case not known to be related to other cases.

b Contacts were defined as people who were exposed to the case during the contagious period (four days before to four days after rash onset).

c Non-immune contacts were defined as people born after 1963 and without vaccination or IgG or proven histoy of disease. 
high (average: 4.2/5) with a large variability in the responses. Epidemiological reports and cantonal communication were particularly well noted ( 4.5 and 4.6 ) as was the collaboration with the partners. The most critical points related to media information and the lack of well-defined roles and responsibilities for contact tracing and control measures (3.4 and 3.6).

\section{Discussion}

This outbreak was the largest ever documented in the canton of Geneva. It occurred in the context of an extensive measles epidemic in the neighbouring RhôneAlpes region in France. About one fifth of the cases were imported or related to imported cases, mostly from the bordering département of Haute-Savoie. This does not come as a surprise as the epidemiology of infectious diseases in the canton of Geneva is often closely related to its neighbouring regions for obvious demographic, economic and geographic reasons.

Although national MMR vaccination coverage remains below the threshold required for measles elimination in Switzerland [13-15], it is currently higher in Geneva: $91.7 \%$ for children aged 28 months for two doses, and 92.3\% for children aged between five and six years [1,57]. Data collected locally indicated that the main reason for not vaccinating children were concern for side effects and the belief that natural infection contributed more to better health than vaccination [16]. Progressive accumulation of non-immune persons, however, is inevitable. Combined with multiple introductions of infectious patients into the Geneva community, outbreaks or at least small clusters of cases seem currently unavoidable.

Most cases in this outbreak were adults, many of whom were not aware of their vaccination status. There was a delay in the diagnosis of several cases during the seasonal influenza period between weeks 1 and 7 of 2011 in Geneva, as early presentation of measles can be quite similar to influenza. In some instances, there were multiple consultations before measles was diagnosed. Early consultation of adults presenting with non-specific symptoms prior to the rash may also have contributed to delay in diagnosis. However, only three healthcare-related cases were observed.

Control measures were implemented early for all cases including those whose measles diagnosis had not yet been confirmed. Nevertheless, post-exposure vaccination was often ineffective as it was done too late, especially in siblings. At least 17 close contacts received post-exposure vaccination. Six of them developed measles, of whom five were vaccinated more than 72 hours after exposure.

Although, as expected, the secondary attack rate among unvaccinated household members was high, quarantine of non-immunised relatives, close contacts and classmates, a measure previously implemented in Geneva $[1,2]$, was very effective. The large majority
(68\%) of exposed non-vaccinated or non-immune persons who were quarantined developed measles, but no transmission outside their own families occurred. Data collected during this outbreak documented a $95 \%$ reduction in the risk of community transmission. Even when household transmission was included, quarantine decreased the risk of transmission by $74 \%$. Compliance to quarantine was good and this measure was well accepted. This may, at least in part, have been due to the support from school health services and because parents had been previously informed of this possible consequence of their refusal to have their child vaccinated. Exclusion of children with measles was strictly enforced by school authorities.

The results from the evaluation questionnaire helped us to further define the operational roles of the various partner institutions in case management, contact tracing and contact management. It also confirmed the value of rapid and regular analysis and dissemination of local epidemiological information.

\section{Conclusion and recommendations}

Fairly high MMR vaccination coverage in children as well as early and effective control measures including quarantine probably contributed to reducing the magnitude of this outbreak, especially among school-age children. Although Switzerland adheres to the WHOs objective of eliminating measles in the European region by 2015 , this will require, in addition to a national strategy [17], a common effort of all European countries and regions. Sustained high vaccination coverage, effective surveillance and early control measures including quarantine of non-vaccinated exposed persons should be implemented by all European countries and regions if outbreaks such as this one are to be prevented and virus circulation interrupted.

\section{Acknowledgements}

The authors wish to sincerely thank colleagues of the Epidemiology and infectious diseases section Ms O. Lacour, M Girard, N. Jost, C. Claudet and V. Serena, Professor J.A. Romand, Médecin cantonal, Dr J.L. Richard, Federal Office of Public Health (FOPH), Professor S. Harbarth, C. Ginet, Dr T. Farinelli, Professor T. Perneger and A. Poncet, Geneva University Hospital (HUG), Professor L. Kaiser, Drs P. Cherpillod and S. Cordey, Central virology laboratory (HUG), Geneva private laboratories and physicians, Dr E. Masserey and Ms M. Attinger, Vaud canton, as well as the French health authorities in Annecy, Bourg-en-Bresse and Lyon.

\section{References}

1. Delaporte E, Jeannot E, Sudre P, Wyler Lazarevic CA, Richard JL, Chastonay P. Measles in Geneva between 2003 and 2010: persistence of measles outbreaks despite high immunisation coverage. Euro Surveill. 2011;16(39):pii=19980. Available from: http://www.eurosurveillance.org/ViewArticle. aspx?Articleld $=19980$

2. Delaporte E, Wyler-Lazarevic CA, Richard JL, Sudre P. Contribution des fratries non vaccinées à une flambée de rougeole en Suisse. [Contribution of unvaccinated siblings to a measles outbreak in Switzerland]. Rev Epidemiol Sante Publique. 2004;52(6):493-501. French. http://dx.doi. org/10.1016/S0398-7620(04)99089-X 
3. Federal Office of Public Health (FOPH). Flambée de rougeole à Genève, mars-avril 2007: description et mesures de contrôle. [Measles outbreak in Geneva, March-April 2007: description and control measures]. FOPH Bulletin. 2007;24:435-8. French. Available from: http://www.bag.admin.ch/dokumentation/ publikationen/01435/03542/index.html?lang=fr\&download=N HzLpZig7t,Inp6IoNTU042l2Z6In1ae2IZn4Z2qZpnO2Yuq2Z6gpJ CGd4F6fWym162dpYbUzd,Gpd6emK2Oz9aGodetmqaN19XI2Id voaCUZ,s-

4. Federal Office of Public Health (FOPH). Plan suisse de vaccination 2011 [Swiss vaccination schedule 2011]. FOPH Bulletin. 2011;7:157.

5. Jeannot E, Wyler Lazarevic CA, Duperrex O, Chastonay P. Évolution de la couverture vaccinale de l'année scolaire 2003-2004 à 2007-2008 pour les enfants de cinq à six ans à Genève. [Evolution of vaccine coverage from school year 2003-2004 to 2007-2008, for five- to six-year-old children in Geneva]. Med Mal Infect. 2010;40(1):27-30. French. http:// dx.doi.org/10.1016/j.medmal.2009.06.009 PMid:19615837

6. Jeannot E, Wyler Lazarevic CA, Duperrex O, Chastonay P. Evolution à quatre ans de la couverture vaccinale chez les 13 14 ans à Genève . [Evolution of the immunization coverage of 13 to 14 year-old adolescents in Geneva between four years]. Santé Publique. 2009;21(6):605-11. French. PMid:20429230

7. Golay M, Sudre P. Vaccination des enfants de 28 mois à Genève, Suisse: évolution sur six ans, 1995-2000. [Immunisation of 28 months old children in Geneva, Switzerland: Trend over a 6-year period, 1995-2000]. Soz Praventivmed. 2005;50(5):319-23. http://dx.doi.org/10.1007/ so0038-005-3132-4 PMid:16300176

8. Delaporte E, Richard JL, Wyler Lazarevic CA, Lacour O, Girard M, Ginet C, Iten A, Sudre P. Ongoing measles outbreak, Geneva, Switzerland, January to March 2011. Euro Surveill. 2011;16(10):pii=19815. Available from: www.eurosurveillance. org/ViewArticle.aspx?Articleld $=19815$

9. Numéro spécial rougeole en Rhône-Alpes - Point sur la vague épidémique d'octobre 2010 à septembre 2011. [Special issue on measles in Rhône-Alpes - on the epidemic wave from October 2010 to September 2011]. Bulletin de veille sanitaire Rhône-Alpes. 2011;2. French. Available from: http://www.invs. sante.fr/fr./Publications-et-outils/Bulletin-de-veille-sanitaire/ Tous-les-numeros/Rhone-Alpes/Bulletin-de-veille-sanitaireRhone-Alpes.-Numero-special-rougeole

10. Measles. Case definitions. Stockholm: European Centre for Disease Prevention and Control (ECDC). [Accessed 26 Jan 2013]. Available from: http://ecdc.europa.eu/en/activities/ surveillance/euvac/case definition/pages/measles.aspx

11. Reiczigel J, Abonyi-Tóth Z, Singer J. An exact confidence set for two binomial proportions and exact unconditional confidence intervals for the difference and ratio of proportions. Computational Statistics and Data Analysis. 2008; 52:504653. http://dx.doi.org/10.1016/j.csda.2008.04.032

12. Lacroix L, Delaporte E, Siegrist CA, Sudre P, Wyler Lazarevic CA, Gervaix A. Rougeole: diagnostic et prise en charge d'une maladie toujours plus d'actualité. [Measles: diagnosis and management of a disease of increasing relevance]. Rev Med Suisse. 2008;4(152):920-4. French .PMid:18578433

13. Anderson RM, May RM. Immunisation and herd immunity. Lancet. 1990;335(8690):641-5. http://dx.doi. org/10.1016/0140-6736(90)90420-A

14. Richard JL, Masserey Spicher V. Large measles epidemic in Switzerland from 2006 to 2009: consequences for the elimination of measles in Europe. Euro Surveill. 2009;14(50): pii=19443. Available from: http://www. eurosurveillance.org/ViewArticle.aspx?Articleld=19443 PMid:20070934

15. Federal Office of Public Health (FOPH). Couverture vaccinale en Suisse 2005-2007. [Vaccination coverage in Switzerland 2005-2007]. FOPH Bulletin. 2010;11:367-77. French.

Available from: http://www.bag.admin.ch/dokumentation/ publikationen/01435/07914/index.html?lang $=$ fr\&download $=\mathrm{N}$ HzLpZig7t, Inp6IoNTU042l2ZZIn1ae2IZn4Z2qZpnO2Yuq2Z6gpJ CJdH552ym162dpYbUzd,Gpd6emK2Oz9aGodetmqaN19XI2Idv oaCUZ,s-

16. Burton-Jeangros C, Golay M, Sudre P. Adhésion et résistance aux vaccinations infantiles: une étude auprès de mères suisses. [Compliance and resistance to child-immunisation: a study among Swiss mothers]. Rev Epidemiol Sante Publique. 2005;53(4):341-50. French. http://dx.doi.org/10.1016/ So398-7620(05)84616-4

17. Federal Office of Public Health (FOPH). Stratégie nationale d'élimination de la rougeole 2011-2015. [National strategy for the elimination of measles 2011-2015]. Berne: FOPH. [Accessed: 26 Jan 2013]. French. Available from: http://www.bag.admin. $\mathrm{ch} /$ themen/medizin/00682/00684/01087/index.html?lang=fr 